\title{
Diagnóstico de tuberculosis: desde lo tradicional hasta el desarrollo actual
}

Diagnosis of tuberculosis: from the traditional to the present development

\author{
Marisol Jaramillo-Grajales PhD', Robinson A. Torres-Villa PhD', \\ Elizabeth Pabón-Gelves PhD ${ }^{3}$, Paula A. Marín-Muñoz MSc', \\ Kaory Barrientos-Urdinola IB ${ }^{5}$, Yeison J. Montagut-Ferizzola PhD, \\ Jaime A. Robledo-Restrepo $\mathrm{PhD}^{7}$
}

\begin{abstract}
Resumen: la tuberculosis es un problema de salud pública que afecta a millones de personas, siendo la cuarta causa de muerte por enfermedad infecciosa en el mundo. En su más reciente reporte, la Organización Mundial de la Salud (OMS) menciona que la infección tuberculosa es curable con un tratamiento adecuado; sin embargo, es una necesidad la detección precoz de casos y la mejora del diagnóstico como medida de control. En esta revisión se presenta una recopilación de los métodos de detección de tuberculosis desde los tradicionales hasta las nuevas alternativas en desarrollo. Como métodos convencionales de diagnóstico para la detección de la tuberculosis se han usado el examen directo con coloración de esputo y el cultivo para determinar la presencia de la micobacteria; estos métodos presentan desventajas importantes que afectan la sensibilidad y tiempo para el diagnóstico. Recientes avances en pruebas rápidas incluyen el desarrollo de técnicas moleculares e inmunoensayos que pueden detectar micobacterias resistentes a antibióticos y anticuerpos de la respuesta inmune del hospedero. Sin embargo, esta enfermedad no cuenta con una prueba de diagnóstico precisa que permita la detección y el diagnóstico rápido con la mínima pérdida de pacientes. Frente a estos retos, en la actualidad se encuentran en desarrollo nuevas pruebas basadas en biosensores mediante el uso de biomarcadores adecuados de la enfermedad.
\end{abstract}

\footnotetext{
' Ingeniera Química, MSc en Biotecnología, candidata a PhD en Biotecnología, Universidad Nacional de Colombia, sede Medellín. Docente-Investigador, Universidad EIA. Envigado, Colombia.

${ }^{2}$ Ingeniero Electrónico, MSc en Ingeniería, PhD en Ingeniería Electrónica. Docente-Investigador, Universidad EIA y Universidad CES. Envigado, Colombia.

${ }^{3}$ Química, PhD en Química. Profesora-Investigadora, Universidad Nacional de Colombia, sede Medellín. Medellín, Colombia. ${ }^{4}$ Bioingeniera, Especialista en Gestión Metrológica Industrial, MSc en Ingeniería Biomédica. Investigadora, Universidad EIA. Envigado, Colombia. Correspondencia: Calle 25 Sur 42-73. Teléfono: 5743549090 ext.688. Correo electrónico: paula.marin@eia.edu.co ${ }^{5}$ Ingeniera Biomédica. Investigadora, Universidad EIA. Envigado, Colombia.

${ }^{6}$ Ingeniero Electrónico, PhD en Ingeniería Electrónica. Docente-Investigador, Universidad EIA. Envigado, Colombia.

${ }^{7}$ Médico, Especialista en Microbiología Médica, PhD en Ciencias Médicas. Investigador, Unidad de Bacteriología y Micobacterias, Corporación para Investigaciones Biológicas (CIB)-Universidad Pontifica Bolivariana (UPB). Medellín, Colombia.

Conflicto de intereses: los autores declaran que no tienen conflicto de intereses

Medicina \& Laboratorio 2015; 21: 311-332

Módulo I (La Clínica y el Laboratorio), número I I I. Editora Médica Colombiana S.A. $2015^{\odot}$

Recibido el I 4 de julio de 2015; aceptado el 28 de agosto de 2015
}

Medicina \& Laboratorio Volumen 21, Números 7-8, 2015. 
Palabras clave: tuberculosis, diagnóstico, biomarcadores, prueba de tuberculina, medios de cultivo, biosensores.

\begin{abstract}
Tuberculosis is a public health problem that affects millions of people, being the fourth common cause of death due infectious disease in the world. In a recent report, the World Health Organization (WHO) argues that tuberculosis infection is curable with proper treatment; however its early detection and improved diagnosis tools are necessary for tuberculosis control. In this review, a compilation of methods for detecting tuberculosis from traditional to new developing alternatives are presented. As conventional diagnostic methods for detecting tuberculosis have been used direct sputum smear and cell culture to establish the presence of mycobacteria; however, these methods have significant disadvantages which include sensitivity and time for diagnosis. Among recent advances in rapid tests are the development of molecular techniques and immunoassays to detect antibiotics mycobacteria resistance and antibodies from the host immune response. However, this disease does not have an accuracy diagnostic test that allows rapid detection and diagnosis with minimal loss of patients. Currently, to deal with these challenges, new tests based on biosensors are developing, using appropriate biomarkers of disease.
\end{abstract}

Key words: tuberculosis, diagnosis, biomarkers, tuberculin test, culture media, biosensors.

Jaramillo-Grajales M, Torres-Villa RA, Pabón-Gelves E, Marín-Muñoz PA, Barrientos-Urdinola K, Montagut-Ferizzola YJ, Robledo-Restrepo JA. Diagnóstico de tuberculosis: desde lo tradicional hasta el desarrollo actual. Medicina \& Laboratorio 2015; 21 : 311-332.

L a tuberculosis es una enfermedad infecciosa causada por el bacilo Mycobacterium tuberculosis, que afecta frecuentemente a los seres humanos y representa altas tasas de morbimortalidad, por lo que es considerada un problema de salud pública en el mundo [I]. Algunos estudios han mostrado que la tuberculosis aumenta el riesgo de padecer cáncer de pulmón [2], el cual representa, a su vez, la causa de muerte más común entre las enfermedades no transmisibles, aportando 1.824 .70 I muertes en el 2012 [3]. En los últimos años, algunos factores de riesgo tales como la desnutrición, el tabaquismo, la inmunosupresión por la infección con el virus de la inmunodeficiencia humana $(\mathrm{VIH})$, la diabetes, el alcoholismo y el bajo nivel socioeconómico han influido en el aumento del número de infectados con tuberculosis [4].

La Organización Mundial de la Salud (OMS) reportó para el año 2014 alrededor de 9.600.000 casos nuevos y 1.500 .000 de muertes, siendo este número inaceptable dado que la mayoría de casos son prevenibles con un diagnóstico rápido y el comienzo de un tratamiento oportuno y adecuado. A principios de los noventa, la Organización Mundial de la Salud estableció la estrategia "Alto a la Tuberculosis», basada en el enfoque DOTS (del inglés, Direct Observed Treatment Short-Course) para abordar los principales problemas que plantea la enfermedad y controlar la diseminación. Con la implementación de esta estrategia para el 2014, la tasa de mortalidad y prevalencia de la tuberculosis disminuyó en un $47 \%$ y $42 \%$, respectivamente, en relación a 1990 [I]. No obstante, el progreso no fue suficiente para cumplir con las metas propuestas en los Objetivos de Desarrollo del Milenio de la Organización de las Naciones Unidas (ONU) para el año 2015 y 2050, donde se esperaba una reducción de la prevalencia y la mortalidad por tuberculosis en un $50 \%$ en el año 2015 con respecto a 1990 y un índice de prevalencia significativamente bajo para el año 2050 (menos de un caso por cada millón de 
personas por año) [5]. Para alcanzar el cumplimiento de esta última meta, la tasa de incidencia de tuberculosis debe disminuir en promedio un 16\% por año en los próximos 40 años [6]; sin embargo, el promedio de reducción fue de 1,5\% por año entre 2000 y 2014 [ I].

Con el fin de acelerar el progreso en la lucha contra la epidemia global de tuberculosis, la Asamblea de la Organización Mundial de la Salud adoptó en mayo de 2014 la estrategia «Fin a la TB», la cual establece una reducción del $80 \%$ en la tasa de incidencia y una disminución del $90 \%$ en el número de muertes por tuberculosis para el año 2030, con respecto a los valores presentados en 2015. Esta estrategia se basa en tres pilares de acción: la atención y prevención integrada centrada en el paciente, la definición de políticas y sistemas que permitan la prevención y la atención de la enfermedad y la intensificación en la investigación e innovación orientada al descubrimiento y desarrollo de nuevas herramientas diagnósticas, intervenciones y estrategias [7].

Los avances en el diagnóstico de la tuberculosis están relacionados con el desarrollo de técnicas basadas en la biología molecular, las cuales suministran resultados en horas y, comparados con los métodos tradicionales de diagnóstico, tienen ventajas notables [8]. No obstante, la implementación de estos métodos a gran escala se ve limitada por su alto costo y la exigencia del uso de equipos sofisticados que necesitan calibración y mantenimiento constante, suministro eléctrico estable y continuo, aire acondicionado, entre otros. Muchos de estos requerimientos no están disponibles en las regiones geográficas aisladas y de difícil acceso, donde el diagnóstico de la enfermedad continúa siendo mediante la coloración de esputo y el cultivo; técnicas usadas tradicionalmente y por décadas, cuyos resultados demoran días y su confirmación semanas o meses. Por lo tanto, se ha generado la necesidad de buscar nuevas alternativas de detección y el desarrollo de nuevos sistemas de diagnóstico que sean eficientes, de fácil manejo, asequibles y aplicables en zonas endémicas que no cuentan con laboratorios especializados [9].

Una de las alternativas para el posible mejoramiento, respecto a los métodos tradicionales, de algunas de las características requeridas para el diagnóstico de la tuberculosis como la portabilidad, el tiempo de respuesta, la especificidad, la sensibilidad y la relación costo-beneficio, ha sido el desarrollo de biosensores [10]. La presente revisión describe, en términos generales, la patogénesis de la tuberculosis y resume los principales métodos de detección desde los más tradicionales, como la baciloscopia y el cultivo, hasta los más actuales, como las técnicas moleculares, conduciendo a la necesidad de encontrar biomarcadores específicos de la enfermedad y el planteamiento de técnicas novedosas para el diagnóstico como los biosensores. Finalmente, se presenta una visión general de los avances en el desarrollo y las perspectivas de las técnicas de detección y se resalta la necesidad de financiar la investigación de nuevos métodos de diagnóstico para la tuberculosis.

\section{Mycobacterium tuberculosis: agente patógeno causante de la enfermedad}

El género Mycobacterium está integrado por cerca de 150 especies de bacilos que tienen varios grados de patogenicidad y virulencia en los humanos [I l], los cuales se caracterizan por tener una pared celular rica en lípidos que retiene el colorante carbol fucsina, incluso en la presencia de alcohol ácido. La tuberculosis es causada por diferentes especies de micobacterias que forman parte de un complejo denominadas colectivamente como bacilos 
tuberculosos. A este complejo pertenecen: Mycobacterium tuberculosis, Mycobacterium bovis, Mycobacterium africanum y Mycobacterium microti. La tuberculosis producida por Mycobacterium tuberculosis es la más importante desde el punto de vista sanitario por ser el agente más significativo y frecuente de la enfermedad en los humanos [12].

Mycobacterium tuberculosis, conocido como bacilo de Koch, es una bacteria aerobia estricta y de lenta multiplicación. La envoltura celular de esta micobacteria se caracteriza por la presencia de una variedad de lípidos complejos que constituyen el 60\% de su peso total, lo cual le confiere una baja permeabilidad, lo que contribuye a la dificultad para combatir las enfermedades micobacterianas, dotando al organismo con resistencia innata a los agentes terapéuticos y a las defensas del hospedero [13]. La tuberculosis se puede desarrollar como una infección latente o una enfermedad activa; la forma latente implica un estado reversible de la bacteria en el cual las células pueden permanecer largo tiempo sin dividirse [14], mientras que la enfermedad activa corresponde a la forma sintomática en la que los bacilos tuberculosos se replican causando daños en los tejidos. La enfermedad se puede contraer cuando un individuo inhala los núcleos goticulares dispersos en el aire, los cuales contienen los bacilos, provenientes de un paciente con tuberculosis pulmonar activa, expulsados al toser, estornudar, hablar o escupir [15].

Los datos reportados por la Organización Mundial de la Salud indican que aproximadamente tres mil millones de personas en el mundo tienen la infección latente de tuberculosis y sólo una pequeña proporción (5\% al 15\%) desarrollará la forma activa de la enfermedad durante el transcurso de su vida. Sin embargo, la probabilidad de desarrollar tuberculosis es mucho más alta para las personas infectadas por el VIH por el compromiso de su sistema inmunitario [I]. De acuerdo a las condiciones ambientales y genéticas del hospedero como la inmunosupresión [16, I7], las variaciones en la hemaglutinina de unión a la heparina (HBHA; del inglés, Heparin-binding hemagglutinin) de la micobacteria [18] y el genotipo de ciertas cepas como el Beijing [19], se puede dar la diseminación de los bacilos de Mycobacterium tuberculosis a los pulmones (tuberculosis pulmonar) o a otros sitios del organismo del hospedero (tuberculosis extrapulmonar) [20], tales como los ganglios linfáticos, la pleura, el tejido cutáneo, el abdomen, el sistema gastrointestinal y los huesos [2 I]. En 2013, la Organización Mundial de la Salud reportó 4.600 .000 casos de tuberculosis pulmonar y 800.000 de tuberculosis extrapulmonar, respecto a los 5.400 .000 de pacientes que presentaron la enfermedad por primera vez [22].

\section{Métodos de diagnóstico para la tuberculosis}

La tuberculosis es una enfermedad infecciosa que en la actualidad carece de un método de diagnóstico rápido y preciso, lo que obstaculiza el comienzo oportuno del tratamiento. Se han identificado varias dificultades que interfieren con la detección rápida y efectiva de la tuberculosis, entre las que se incluyen: a) la falta de una prueba para diagnosticar tuberculosis latente que la diferencie de la enfermedad activa, b) la falta de validación accesible y rápida para potenciales biomarcadores de la enfermedad, c) la falta de una prueba exacta y rápida de diagnóstico que de paso rápidamente a un tratamiento adecuado de la enfermedad, d) la falta de ensayos que valoren la resistencia a los medicamentos durante el tratamiento de 
la tuberculosis y e) la falta de financiamiento de proyectos para el desarrollo de pruebas rápidas de diagnóstico clínico [23].

Las pruebas existentes para el diagnóstico de la tuberculosis varían en sensibilidad, especificidad, velocidad en la entrega de resultados y costo. A continuación se describen, de manera general, las técnicas de detección tradicionales como la prueba de la tuberculina, la baciloscopia y el cultivo, y los desarrollos más recientes como los métodos moleculares y los serodiagnósticos.

\section{Prueba de intradermoreacción a la tuberculina (PPD)}

La prueba cutánea PPD (del inglés, Purified Protein Derivative) se basa en una reacción de hipersensibilidad como respuesta al contacto con una mezcla de antígenos del complejo de bacilos tuberculosos. La presencia de una induración en la zona de aplicación de más de $10 \mathrm{~mm}$ después de 48 a 72 horas de la inyección con PPD sugiere que los pacientes son propensos a desarrollar tuberculosis en el futuro mientras que una reacción de más de $20 \mathrm{~mm}$ se interpreta como enfermedad activa (véase figura |). Sin embargo, la alta reactividad cruzada de la tuberculina confunde la interpretación de la positividad de la prueba cutánea de las personas que tienen ante-

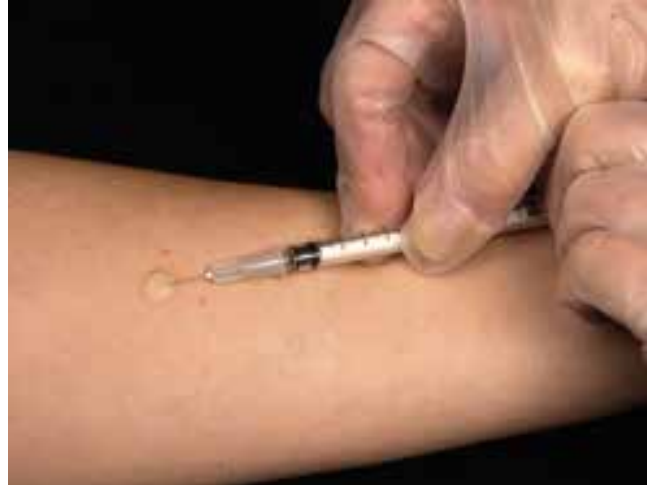

Figura I. Prueba de intradermoreacción a la tuberculina (PPD). Fotografía tomada de la Biblioteca de Imágenes de Salud Pública (PHIL) de los Centros para el Control y Prevención de Enfermedades, con número de identificación \# 6806 (Greg Knobloch). cedentes de vacunación con BCG (Bacillus de Calmette y Guérin) y de las personas que viven o son originarias de las áreas geográficas donde existe una elevada carga ambiental de micobacterias no tuberculosas. En este sentido se encuentran en desarrollo estudios con proteínas recombinantes purificadas que han demostrado mayor discriminación de las especies de micobacterias en la prueba cutánea [24-26].

La PPD es una prueba relativamente fácil de implementar; además, requiere escasa tecnología, es asequible y fácil de interpretar. Esta prueba es útil para identificar a individuos con alto riesgo de enfermarse con tuberculosis, como aquellos con infección por el VIH o personas que están en contacto con pacientes con tuberculosis activa. No obstante, esta prueba no es útil para el diagnóstico preciso de la enfermedad y a menudo es engañosa debido a que presenta resultados falsos negativos y falsos positivos. Al momento del diagnóstico la prueba es falsa negativa entre el $10 \%$ y el $47 \%$ de los pacientes con enfermedad activa. La probabilidad de reacciones falsas negativas aumenta con el grado de la enfermedad y la edad del individuo, incluso más del $95 \%$ de los pacientes a los que se les efectúa la prueba después de un mes o más de tratamiento presentan un resultado positivo. En casos de coinfección por $\mathrm{VIH}$, un porcentaje mucho mayor de pacientes con enfermedad activa tendrá un resultado de la prueba falsa negativa [27]. 


\section{Baciloscopia y cultivo}

La baciloscopia es la prueba más ampliamente usada en el mundo para el diagnóstico de la tuberculosis, la cual se caracteriza por ser sencilla y rápida para detectar la presencia del bacilo mediante valoración microscópica de una muestra de la lesión. La muestra más examinada es el esputo, por corresponder a una lesión pulmonar que se relaciona con el tipo tuberculosis pulmonar, que es la más frecuente. Dado que la enfermedad se puede manifestar en cualquier órgano, con menor frecuencia puede requerirse la valoración de muestras muy variadas tales como: orina, líquido cefalorraquídeo, pleural o ascítico, sangre, pus de cavidades abiertas y biopsias. Estas muestras de lesiones extrapulmonares deben ser procesadas siempre de manera adicional por cultivo [28]. No obstante, la baciloscopia de esputo no es una prueba específica para Mycobacterium tuberculosis debido a que todas las micobacterias son bacilos ácido-alcohol resistentes (BAAR), es decir, que tienen la propiedad de captar en su pared la fucsina fenicada (color fucsia) o auramina (color amarillo fluorescente) y retenerla aún con la acción de decolorantes como la mezcla de ácido y alcohol (véase figura 2) [29].

A

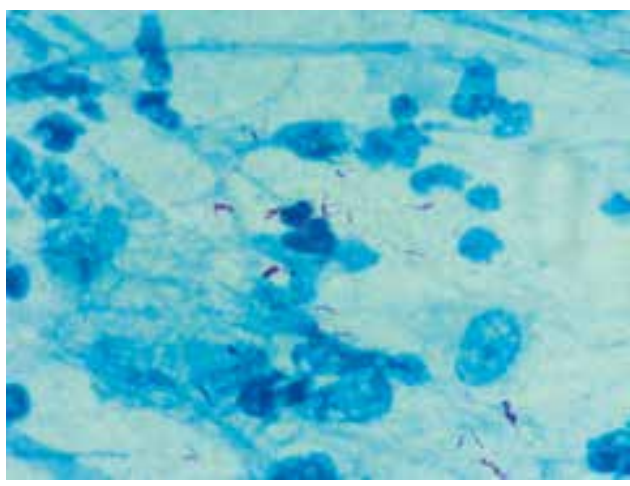

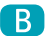

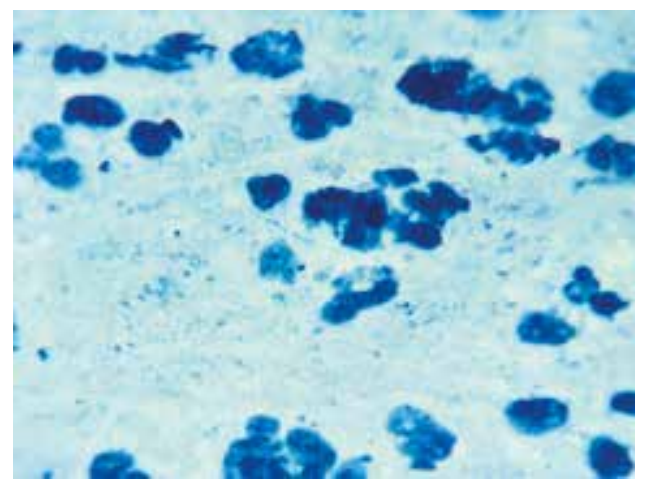

Figura 2. Baciloscopia de esputo teñida con Ziehl-Neelsen (A) positiva (+++) y (B) negativa para bacilos ácido alcohol resistentes (BAAR). Cortesía de la Escuela de Microbiología, Universidad de Antioquia. Medellín, Colombia.

La coloración de Ziehl-Neelsen en extendido o frotis de la muestra es la técnica más apropiada para ser utilizada en todos los laboratorios de los países de América Latina, recomendada por la Organización Mundial de la Salud y la Unión Internacional Contra la Tuberculosis y Enfermedades Respiratorias por ser la que asegura resultados reproducibles con un entrenamiento relativamente simple y con un bajo costo para su implementación [30]. Entre los inconvenientes de la baciloscopia se encuentra que tiene baja sensibilidad y la detección requiere un mínimo de carga bacilar por muestra de 5.000 a 10.000 bacilos $/ \mathrm{mL}$ para arrojar un diagnóstico positivo. La sensibilidad informada de un frotis único de esputo es del $22 \%$ al $43 \%$, presentando un aumento de la tasa de detección cuando se analizan dos o tres frotis en dos días, por lo que sólo alrededor del 50\% al 70\% de los pacientes con tuberculosis pulmonar activa tienen extendidos positivos [3। ]. Para que la baciloscopia sea una buena herramienta de diagnóstico y control de la enfermedad, además de la calidad técnica es necesaria la calidad de los registros, de los informes del laboratorio y el análisis de la información que produce el laboratorio [32,33]. 
Por su parte, el cultivo de micobacterias es en la actualidad la prueba estándar de referencia para el diagnóstico de la infección por ser una prueba sencilla en su implementación y económica. La técnica consiste en cultivar la muestra de los pacientes en medios de cultivo específicos como el Löwenstein-Jensen en el que, en caso de ser positiva, se debe observar el crecimiento de colonias de color blanco a crema, secas, rugosas, opacas, polimorfas y de dimensiones variables cuando el medio es sólido (véase figura 3) o turbidez si es líquido, seguido de la confirmación morfológica por microscopía a partir del cultivo. Una desventaja de esta prueba radica en el crecimiento lento de Mycobacterium tuberculosis, ya que puede transcurrir mucho tiempo desde el momento en que se obtiene la muestra hasta el que se observa algún crecimiento (cultivo líquido de cinco a 10 días, sólido de cuatro a ocho semanas), favoreciendo la diseminación de la bacteria en el caso de pacientes activos sin tratamiento [34]. Por otra parte, los medios de cultivo son susceptibles a la contaminación, ocasionando aún más retraso en el diagnóstico. Otro requerimiento importante para la realización de cultivos es la infraestructura sofisticada de los laboratorios de bioseguridad, generalmente de nivel III [35,36].
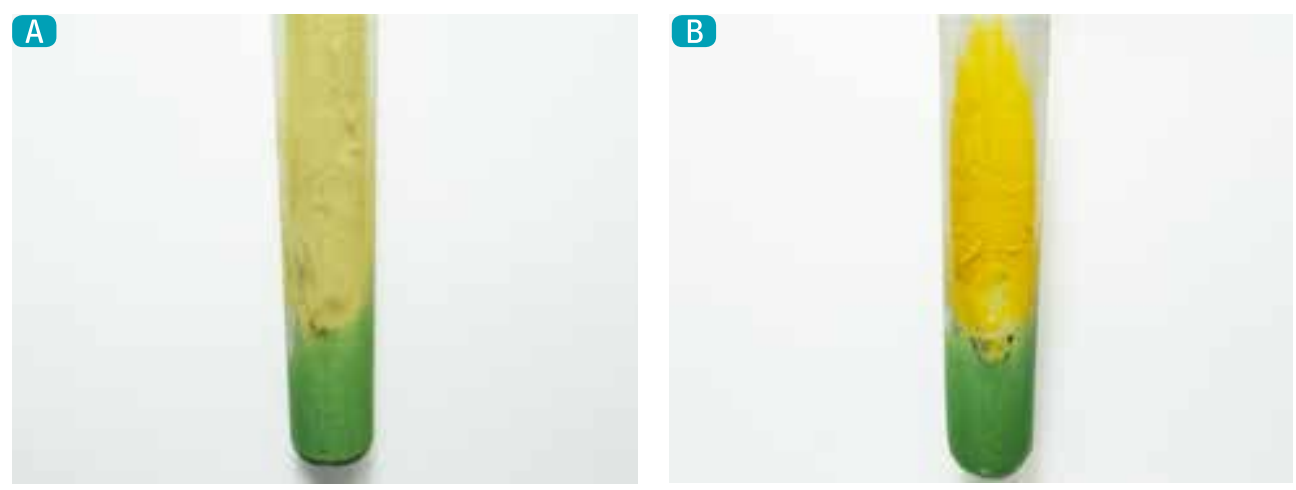

Figura 3. Cultivo de esputo en medio de Löwenstein-Jensen. Colonias de (A) Mycobacterium tuberculosis y (B) Mycobacterium no-tuberculosis. Cortesía de la Escuela de Microbiología, Universidad de Antioquia. Medellín, Colombia.

Ante estas desventajas se han planteado nuevas alternativas para sustituir los cultivos tradicionales con sistemas de radiocultivo líquido automatizado, en los cuales se emplea como única fuente de carbono el Palmitato- $\mathrm{C}^{14}$. Estos sistemas funcionan detectando los desechos metabólicos gaseosos radioactivos, que se generan entre 10 y 15 días de cultivo, indicando el crecimiento de la bacteria [37]. Este método posibilita una detección más rápida, pues puede detectar crecimiento del bacilo en una semana en pacientes con frotis positivo y en dos semanas en aquellos con frotis negativo; además, es un método más sensible que el cultivo convencional (70\% a 95\% frente a 60\% a 80\%). Sin embargo, el empleo de estos sistemas se ha visto limitado por las dificultades asociadas con la disposición final de los radioisótopos generados [38].

En respuesta a estos inconvenientes se han generado sistemas no radiométricos tales como el sistema automatizado BacT/ALERT ${ }^{\circledR}$ MB (BioMérieux, Marcy-l'Étoile, Francia) y el tubo indicador de crecimiento micobacteriano, los cuales presentan niveles de eficiencia diferentes y funcionan midiendo cambios en la presión de gases, el consumo de oxígeno y la 
producción de $\mathrm{CO}_{2}$, ya sea de forma fluorimétrica o colorimétrica. De forma general, estos sistemas permiten detectar micobacterias en 14 días y en la mayoría de las muestras hasta en 21 días. La desventaja sigue siendo el largo tiempo para establecer el diagnóstico y los altos costos, que limitan su uso en los países de mayor prevalencia de la enfermedad pero de escasos recursos [39].

La técnica de cultivo de micobacterias es muy sensible, permitiendo identificar muy pocas micobacterias por muestra [39] y el límite de detección es de unos 100 micobacterias $/ \mathrm{mL}$, mucho más sensible que la baciloscopia. Además, posibilita la identificación de especies micobacterianas por medio de ciertas características como las propiedades bioquímicas. La baciloscopia, por su parte, no puede diferenciar en forma confiable entre las diferentes micobacterias patógenas y no patógenas, que son todas BAAR y de morfología similar. Es por esto que para el diagnóstico de la tuberculosis, tanto la sensibilidad como la especificidad de los métodos de cultivos son mucho mejores comparados con la baciloscopia [40].

\section{Técnicas moleculares}

Las técnicas moleculares se constituyen en los avances más recientes y validados para el diagnóstico de la tuberculosis. Estas pruebas permiten incluso la tipificación de las micobacterias en aquellas muestras donde los métodos de cultivo y otras técnicas convencionales de detección son negativas. Todas las pruebas moleculares tienen tres etapas generales para su desarrollo: a) extracción de ácidos nucleicos, que debe realizarse en un laboratorio nivel III de bioseguridad (duración 24 a 48 horas), b) amplificación, donde los ácidos nucleicos de la muestra son amplificados mediante la reacción en cadena de la polimerasa PCR (del inglés, Polymerase Chain Reaction) de forma que pueda ser detectada (duración de tres a cuatro horas) y c) detección, que incluye el uso de las técnicas de electroforesis,

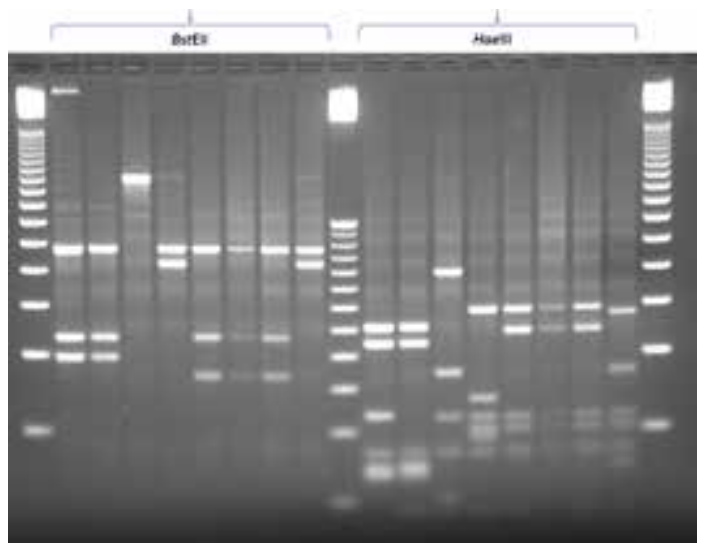

Figura 4. Identificación de especies de micobacterias utilizando la técnica de PRA-hsp65. La amplificación del gen de la proteína de choque térmico hsp65 y su posterior digestión con dos enzimas de restricción (BstEll y Haell ) generan fragmentos de ADN cuyo número y tamaño son característicos de las especies de micobacterias más comunes. Carriles I: Mycobacterium kansasii; carriles 2. Mycobacterium gordonae; carriles 3: Mycobacterium confluentis; carriles 4 y 8: Mycobacterium abscessus; carriles 5,6 y 7 : Mycobacterium fortuitum. ensayos de hibridación empleando sondas y la detección en tiempo real (duración cuatro horas) [4I]. Además, se pueden utilizar en la identificación de especies mediante la técnica de análisis de restricción de productos de PCR (PRA; del inglés, PCR-restriction enzyme analysis)-hsp65 (véase figura 4) [42].

El descubrimiento de secuencias específicas de las micobacterias ha hecho posible mejorar la especificidad de las técnicas moleculares y emplear sondas o sistemas de amplificación de diferentes segmentos de ADN, muchas de las cuales se encuentran disponibles en el mercado. Además, se ha implementado el uso de sondas que tienen como blanco el ARN ribosomal, las cuales son entre 10 y 100 veces más sensibles que las que utilizan el ADN; por lo tanto, se 
pueden utilizar directamente para la detección [43]. Utilizando una técnica molecular con la reacción en cadena de la polimerasa se puede obtener una sensibilidad del 95\% y una especificidad del $98 \%$ para muestras de frotis positivo y una sensibilidad del $48 \%$ al $53 \%$ en las muestras de esputo con frotis negativos, lo que significa que la tasa de resultados falsos positivos y negativos puede ser muy baja [44]. La mayor ventaja de este tipo de pruebas es su rapidez, ya que se obtienen resultados en un lapso de tres días comparadas con el cultivo que puede tardar semanas [45].

La desventaja de las técnicas moleculares radica en la necesidad de equipos robustos y complejos, así como de personal altamente capacitado para realizar las pruebas, lo que dificulta su uso en sitios de baja y mediana infraestructura; además, las muestras generalmente deben ser sometidas a un proceso de amplificación antes de la hibridación para aumentar su sensibilidad, incrementando la probabilidad de contaminación. Por último, este método no diferencia entre los bacilos vivos y los muertos, por lo que no es un método apto para hacer seguimiento en pacientes en tratamiento [46,47]. Por otra parte, la innovación en este tipo de tecnología basada en la reacción en cadena de la polimerasa ha transformado el diagnóstico del VIH y se está aplicando, cada vez más, para el diagnóstico de la tuberculosis.

En términos de costos, el precio de una prueba tipo reacción en cadena de la polimerasa para $\mathrm{VIH}$ ha disminuido desde que salió al mercado por primera vez. En el 2005, el precio medio mínimo era de US\$3I y para el 2012 fue de US\$2I. Esta disminución en costos permite que el desarrollo de las técnicas moleculares para la tuberculosis sea cada vez más probable $[48,49]$. En general, las técnicas moleculares han presentado grandes avances en el diagnóstico de la tuberculosis en los últimos años; en el 20 l 0, la Organización Mundial de la Salud avaló la primera prueba molecular rápida que puede ser usada simultáneamente para la detección de tuberculosis pulmonar y tuberculosis resistente al antibiótico rifampicina, conocida como Xpert MTB/Rif ${ }^{\circledR}$ (Cepheid, California, Estados Unidos). La sensibilidad de esta prueba es mucho mejor que la baciloscopia de esputo y comparable a la del cultivo en medio sólido. Para el 2015 se esperan resultados de estudios realizados con esta prueba específica, con la posibilidad de ser usada para el diagnóstico de la tuberculosis pulmonar, extrapulmonar y pediátrica [50].

\section{Métodos serológicos}

Desde hace varias décadas se han realizado esfuerzos para lograr desarrollar una prueba diagnóstica para la tuberculosis activa basada en la detección de anticuerpos, aunque ninguna prueba ha alcanzado una adecuada sensibilidad y especificidad. La técnica de ELISA (del inglés, Enzyme Linked Immuno Sorbent Assay) se ha utilizado para detectar anticuerpos frente a diversos antígenos purificados tales como CFP-I0 (del inglés, 10-kDa Culture Filtrate Protein), ESAT-6 (del inglés, 6-kDa Early Secreted Antigenic Target), MTB8I y 38kDa, o complejos de antígenos crudos de Mycobacterium tuberculosis como la PPD [5 I,52], pero el poco conocimiento en cuanto a la dinámica de aparición de los anticuerpos, su duración y permanencia después de haber sido curada la enfermedad, las reacciones cruzadas y la ausencia de información relacionada con la regulación y expresión genética de Mycobacterium tuberculosis en diferentes estadios de la enfermedad, hacen difícil la interpretación de los resultados. La sensibilidad de estas pruebas puede variar de acuerdo al antígeno del patógeno utilizado y el nivel de prevalencia de la enfermedad. 
En la figura 5 se esquematizan las etapas en el desarrollo de una ELISA para la detección serológica de la tuberculosis. Los mayores valores de sensibilidad para estas pruebas se han logrado usando muestras de tuberculosis pulmonar con frotis positivo (20\% al 60\%), lo que dificulta el manejo clínico; además, la sensibilidad disminuye aún más cuando las muestras corresponden a frotis negativos (véase tabla I) o con tuberculosis extrapulmonar, que son los casos donde se requiere apoyo diagnóstico de otro tipo $[53,54]$.
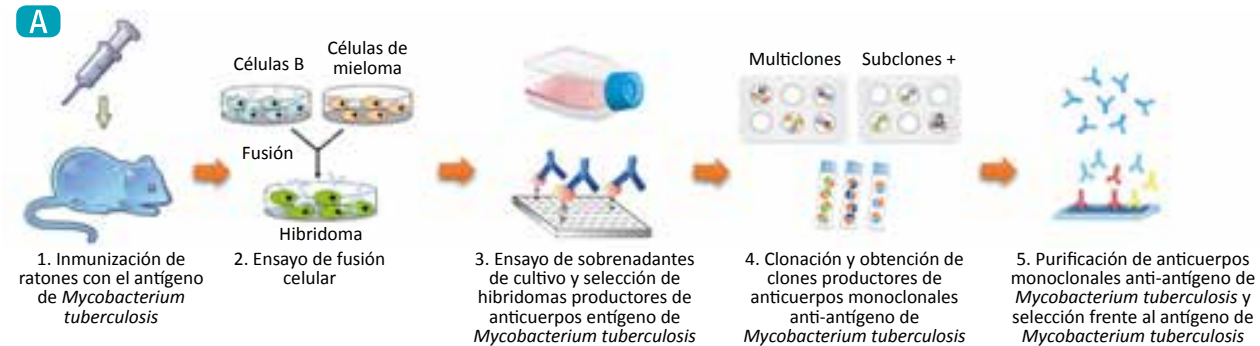

B



- Muestra paciente

AgMtb: antígeno de Mycobacterium tuberculosis

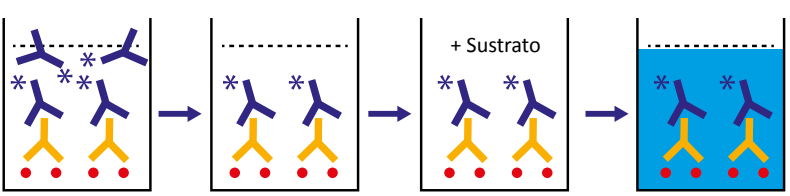

AcMo: Anticuerpos monoclonales anti-antígeno de Mycobacterium tuberculosis

* Anticuerpos secundarios conjugados con enzima

Figura 5. Producción de anticuerpos monoclonales para su uso en ELISA competitiva. A. Producción de anticuerpos monoclonales frente a un antígeno de Mycrobacterium tuberculosis y B. Formato de ELISA competitiva para detección de antígenos de Mycobacterium tuberculosis usando anticuerpos monoclonales. Cortesía de la Línea de biomarcadores, Grupo de Investigación en Ingeniería Biomédica EIA-CES (GIBEC), Medellín, Colombia.

Tabla I. Reactividad de pacientes con frotis positivos y negativos a antígenos recombinantes

\begin{tabular}{lllll}
\multicolumn{1}{c}{ Antígeno } & \multicolumn{2}{c}{ Frotis positivo } & \multicolumn{2}{c}{ Frotis negativo } \\
& Especificidad (\%) & Sensibilidad (\%) & Especificidad (\%) & Sensibilidad (\%) \\
CFP-10 & $>95$ & 28 & $>95$ & 25 \\
38kDa & $>95$ & 47 & $>95$ & 24 \\
\hline ESAT-6 & $>95$ & 27 & $>95$ & 12 \\
Ag27 (antígeno 27) & $>95$ & 60 & $>95$ & 57 \\
\hline
\end{tabular}

\section{Biomarcadores para la detección de Mycobacterium tuberculosis}

Durante los últimos años se han iniciado una serie de estudios a gran escala en la búsqueda de nuevos marcadores biológicos tanto para detectar la infección por Mycobacterium tuberculosis como para valorar el estado de la enfermedad; no obstante, aún no existe un biomarcador para 
tuberculosis validado. Un biomarcador hace referencia a aquella característica encontrada en los sistemas biológicos, que puede ser medida de forma objetiva y evaluada como un indicador de procesos fisiológicos normales, cambios patológicos o respuestas farmacológicas a una intervención terapéutica (véase figura 6) [55,56]. Un biomarcador puede proporcionar información sobre el estado de salud actual y futuro del paciente, así como del conocimiento anticipado de la patogénesis; además, potencialmente, en el contexto de la tuberculosis podrían ser utilizados para predecir el riesgo de reactivación, la erradicación de la forma latente y la eficiencia en el uso de vacunas, al igual que establecer criterios de valoración para los ensayos clínicos o en las pruebas diagnósticas [57].

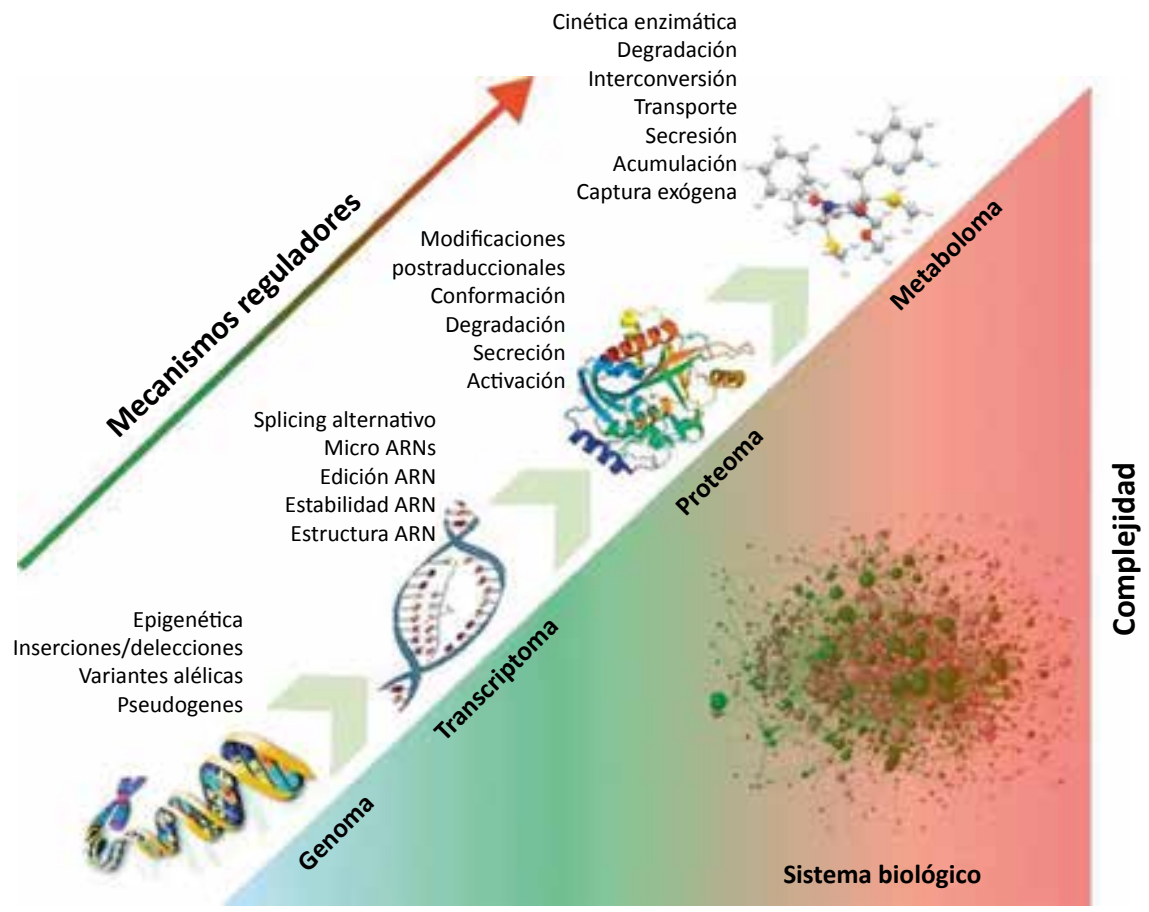

Figura 6. Clasificación de los principales biomarcadores encontrados en sistemas biológicos y las ómicas involucradas para el estudio de los mecanismos reguladores de estas biomoléculas implicados durante los procesos fisiológicos o patológicos.

En 2012, la Fundación Bill \& Melinda Gates (BMGF) invirtió US\$7.700.000 en I0 donaciones centradas en el descubrimiento de biomarcadores para el diagnóstico de tuberculosis, con potencial para ser usados en una prueba simple para la detección de la tuberculosis comparable con la prueba de embarazo comercial; sin embargo, se necesitan de esfuerzos adicionales para acelerar este progreso [58,59]. Actualmente, existen más de 40 estuches comerciales disponibles para detectar biomarcadores para tuberculosis, los cuales usan una variedad de antígenos tales como LAM (lipoarabinomanano), ESAT-6, CFP-10, 38kDa, 16kDa, 6kDa, entre otros. Entre las pruebas inmunodiagnósticas más conocidas se encuentran MycoDot ${ }^{\mathrm{TM}}$ (Mossman Associates Inc., Massachusetts, Estados Unidos), con una sensibilidad del 93\% y una especificidad del 95\% para la detección de LAM, Rapid Test TB (Quorum Diagnostics Inc., Ontario, Canadá) (véase figura 7 ), con una sensibilidad del $25 \%$ y una especificidad del $87 \%$ para el antígeno 
38kDa, y anti-A60 lgG (Anda Biologicals, Strasbourg, Francia) con una sensibilidad del $81 \%$ y una especificidad del 88\%, que utiliza un complejo antigénico. Estos ensayos han presentado inconvenientes cuando existe coinfección con el VIH, encontrándose que su sensibilidad decae más o menos a la mitad en la presencia del virus. Además, las infecciones por micobacterias no tuberculosas pueden causar reacciones cruzadas y con ello una consecuente pérdida de la especificidad, lo que lleva a un incremento en la cantidad de falsos negativos en áreas de alta prevalencia [60].

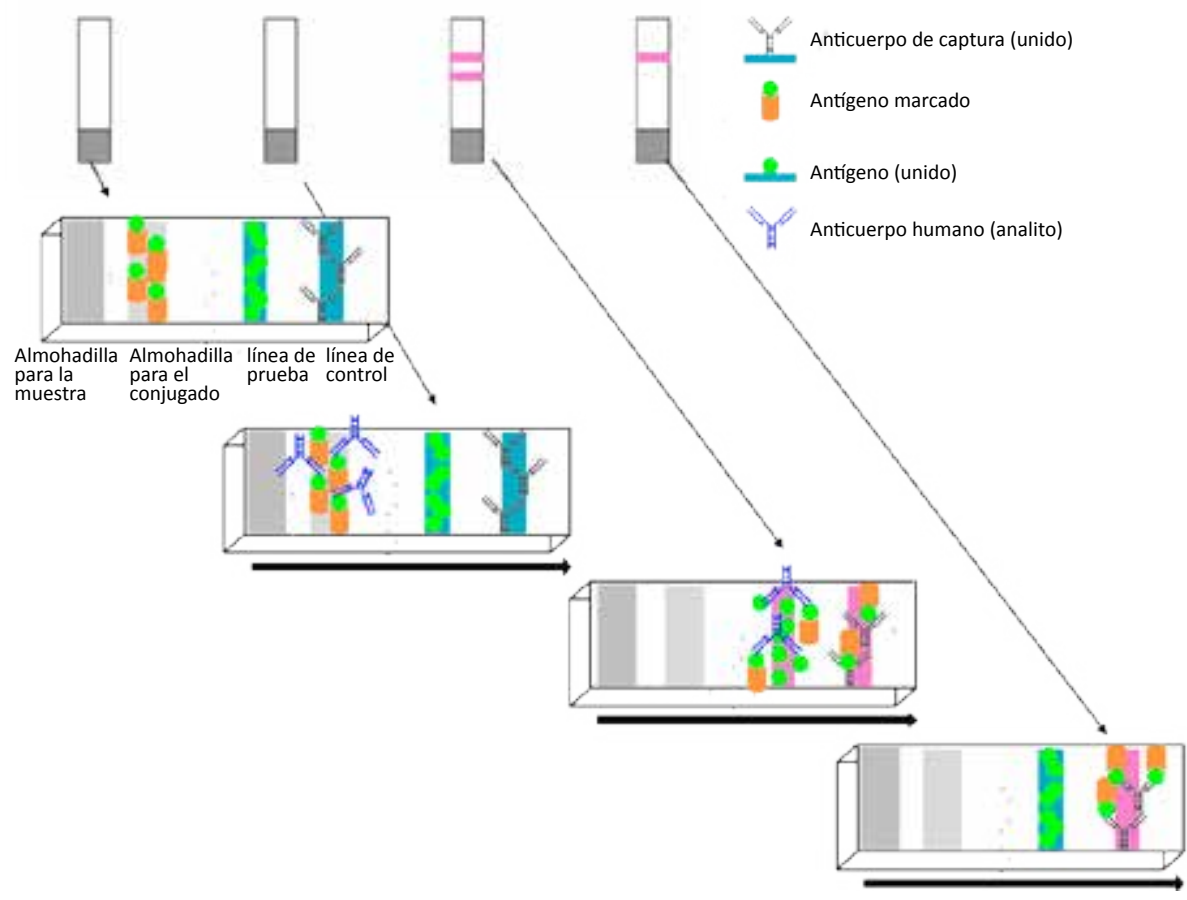

Figura 7. Esquema del funcionamiento de la prueba rápida para tuberculosis (Rapid Test TB, Quorum Diagnostics Inc., Ontario, Canadá).

\section{Alternativas novedosas en el diagnóstico de tuberculosis: el caso de los biosensores}

Dadas las necesidades actuales en el sistema de diagnóstico de la tuberculosis han sido desarrollados nuevos biosensores para responder a los retos propuestos. Estos dispositivos presentan dos cualidades importantes requeridas para el diagnóstico como: a) la rapidez de la prueba, ya que se pueden obtener resultados en un tiempo inferior a una hora, lo que implica, en el caso más favorable, que ningún paciente se pierde durante el diagnóstico y el seguimiento, y b) la portabilidad y relativa simplicidad operativa, haciéndolos muy accesibles al sistema de salud en regiones endémicas vulnerables; que si lograran sensibilidades en el diagnóstico de muestras con frotis negativo del $85 \%$ y especificidades del $97 \%$, podrían salvar alrededor de 392.000 vidas anuales [22]. 
Un biosensor puede ser definido como un dispositivo analítico que utiliza reacciones bioquímicas específicas mediadas por biomoléculas (bioreceptores), tejidos, organelas o células enteras acoplados o inmovilizados a un transductor capaz de transformar una interacción bioquímica en una señal mediable y cuantificable $[61,62]$. Existen diversos tipos de transductores y su uso depende de la aplicación y los parámetros que se quieran medir; los transductores potenciométricos detectan los cambios del potencial ante corrientes constantes, los amperométricos detectan cambios en la corriente bajo potenciales constantes, los ópticos detectan cambios en la transmisión de la luz, los térmicos detectan cambios de temperatura y los piezoeléctricos, como las microbalanzas de cuarzo (QCM; del inglés, Quartz Crystal Microbalance), detectan cambios de masa superficiales (véase figura 8). Cuando el componente biológico inmovilizado sobre la superficie de un transductor es un inmunoreactivo, el biosensor se conoce como inmunosensor $[63,64]$.

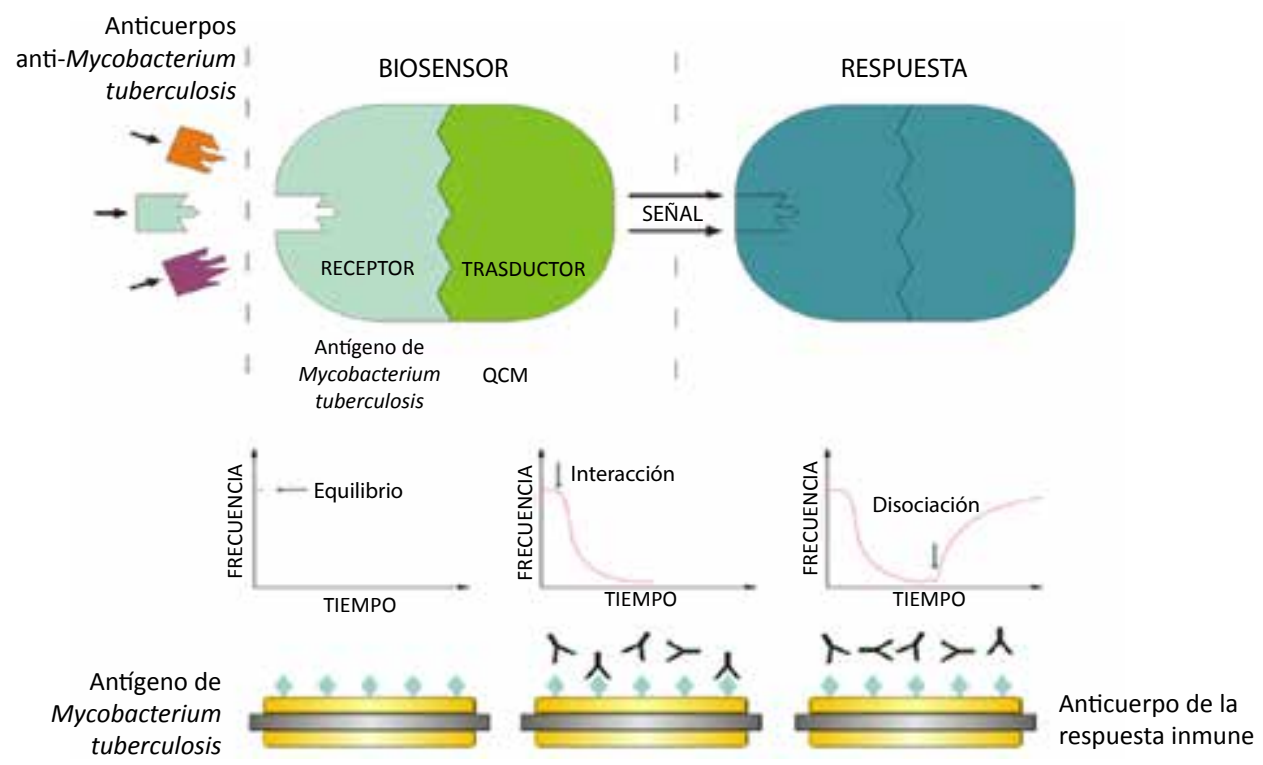

Figura 8. Biosensores para el diagnóstico de tuberculosis. QCM: microbalanzas de cuarzo.

Gracias a los grandes avances en el campo de la electrónica, la nanotecnología y la microfluídica, se han desarrollado una variedad de biosensores para la detección de Mycobacterium tuberculosis, uno de ellos es el inmunosensor piezoeléctrico desarrollado por He y Zhang (2002) [65], en el cual la superficie de una microbalanza de cuarzo fue recubierta con un copolímero de estireno-butadieno-estireno, para inmovilizar anticuerpos anti- Mycobacterium tuberculosis en el transductor. Durante la incubación con Mycobacterium tuberculosis sobre el cristal inmovilizado fue observada la captura de micobacterias en tiempo real mediante la variación de frecuencia como resultado del cambio de masa en la superficie del sensor. Esta tecnología es sencilla, rápida y libre de etiquetas, pero su precisión se afecta por distintas variables de la muestra como la densidad, la viscosidad, 
la constante dieléctrica y la conductividad. Usando esta misma tecnología, Hiatt y Cliffel (20/2) [66] lograron detectar el antígeno lipoarabinomanano (LAM) y el bacilo completo a concentraciones de $8,7 \times 10^{6}$ células $/ \mathrm{mL}$ con anti- LAM y $8,7 \times 10^{5}$ células $/ \mathrm{mL}$ con antiMycobacterium tuberculosis.

En otro trabajo Ren y colaboradores (2008) [67] desarrollaron una plataforma de detección de Mycobacterium tuberculosis basada en la tecnología piezoeléctrica, utilizando un sistema sensor con un cristal de cuarzo piezoeléctrico multicanal en serie (MSPQC; del inglés, Multi-Channel Series Piezoelectric Quartz Cristal). Este sistema consiste en una plataforma de detección multimuestras, acoplado a un microprocesador con salida de datos, usando un transductor oscilador recubierto con plata. Este sistema detectó productos volátiles $\left(\mathrm{NH}_{3}\right.$ y $\left.\mathrm{CO}_{2}\right)$ liberados como resultado del crecimiento de la bacteria, los cuales fueron absorbidos por el hidróxido de potasio $(\mathrm{KOH})$, ocasionando una variación de frecuencia. Comparando los resultados obtenidos con este sistema y una prueba convencional como BACTECTM, MGITTM y Lowenstein-Jensen, la tecnología del cristal de cuarzo piezoeléctrico multicanal en serie es más económica (menos de US\$ I.000 para la configuración y US\$ 4,2 por ensayo); sin embargo, requiere de dos a cuatro días para el cultivo de Mycobacterium tuberculosis, así como del pretratamiento de las muestras para eliminar la contaminación potencial con otras bacterias.

Otro tipo de biosensor para la detección de Mycobacterium tuberculosis es el analizador de aliento fluorométrico o sistema de biosensores rápidos (RBS; del inglés, Rapid Biosensor Systems). Este sistema consiste en un dispositivo portátil que cuenta con un tubo desechable sobre el cual el paciente tose. En el caso de una muestra positiva, el antígeno nativo de Mycobacterium tuberculosis (Ag85B) desplaza a su análogo en el tubo y es detectado por un instrumento que contiene un láser y un fotomultiplicador, haciendo que se obtenga un cambio de señal en un tiempo de 10 minutos. En pruebas de campo realizadas, el dispositivo del sistema de biosensores rápidos obtuvo una sensibilidad del $74 \%$ y una especificidad del 79\%; parámetros que deben ser considerablemente mejorados. Esta tecnología definitivamente no reemplaza la baciloscopia pero, una vez mejorada, podría ser utilizada en pacientes a los que les es difícil suministrar una muestra de esputo, como los niños y los ancianos [68].

Otro desarrollo importante es el biosensor de resonancia magnética nuclear a base de chip (NMR; del inglés, Chip-nuclear Magnetic Resonance) que puede detectar Mycobacterium tuberculosis presente en muestras de esputo sin tratar en un tiempo de 30 minutos. Esta tecnología utiliza partículas magnéticas recubiertas con anticuerpos específicos contra los biomarcadores diana, requiere pequeños volúmenes de muestra $(5 \mu \mathrm{L}$ a $10 \mu \mathrm{L})$ y presenta tiempos de respuestas realmente cortos. En cuanto a costos se puede decir que el biosensor de resonancia magnética nuclear cuesta menos de US\$200 y el microchip desechable cuesta alrededor de US\$ I, lo que convierte a esta tecnología en una potencialmente adecuada para ser implementada en regiones con pocos recursos $[69,70]$.

Los inmunosensores enzimáticos son uno de los métodos más comunes para el diagnóstico de la tuberculosis. En el trabajo de Díaz-Gonzalez y colaboradores (2005) [7l] se usó un dispositivo que trabajaba con el principio de ELISA en el formato sándwich para la de- 
tección de un inmunocomplejo, el cual es capturado por un electrodo de carbono serigrafiado modificado con estreptavidiva (SPCE; del inglés, Screen-Printed Carbon Electrode). En este ensayo se emplearon dos antígenos de Mycobacterium tuberculosis, el Ag 360 y el Ag 23I, con sus respectivos anticuerpos monoclonales. El inmunocomplejo fue capturado por anticuerpos anti- Mycobacterium tuberculosis inmovilizados sobre la superficie del sensor mediante la interacción biotina/estreptividina. La detección del inmunocomplejo se realiza usando un anticuerpo genérico anti-lgG conjugado con una enzima fosfatasa alcalina. La enzima reacciona con 3-indoxil fosfato (3-IP) permitiendo una detección voltamperométrica. El límite de detección para este dispositivo fue de I ng/mL para el antígeno Ag23 I con entrega de resultados en un tiempo significativo de $4 \mathrm{~h}[\mathrm{I0,7I}]$.

Otro tipo de sensor electroquímico fue desarrollado para la detección de ADN genómico de Mycobacterium tuberculosis basado en el doble etiquetado de nanopartículas de oro con fosfatasa alcalina y oligonucleótidos de ADN específicos. Este método presentó un límite de detección de 1,25 ng/mL para la detección de ADN de Mycobacterium tuberculosis con una sensibilidad y especificidad comparables a la reacción en cadena de la polimerasa a partir de muestras de esputo. Los requisitos para el desarrollo de esta técnica siguen siendo rigurosos, tales como los múltiples lavados, el control de la temperatura y los largos tiempos de incubación [72].

En la tabla 2 se resumen y comparan los biosensores antes descritos encontrados hasta hoy para la detección de Mycobacterium tuberculosis, mostrando el biomarcador o el analito seleccionado y el límite de detección reportado para cada uno de ellos [73].

\begin{tabular}{|c|c|c|c|}
\hline Tecnología & Biomarcador & $\begin{array}{l}\text { Límite de } \\
\text { detección }\end{array}$ & Referencia \\
\hline Microbalanzas de cuarzo (QCM) & Bacilo completo de Mycobacterium tuberculosis & $10 \mathrm{UFC} / \mathrm{mL}$ & {$[67]$} \\
\hline Microbalanzas de cuarzo (QCM) & Antígeno lipoarabinomanano & $\begin{array}{l}8,7 \times 10^{5} \\
\text { células } / \mathrm{mL}\end{array}$ & {$[66]$} \\
\hline $\begin{array}{l}\text { Cristal de cuarzo piezoeléctrico } \\
\text { multicanal en serie (MSPQC) }\end{array}$ & Absorción de $\mathrm{NH}_{3}$ y $\mathrm{CO}_{2}$ & $10^{5} \mathrm{UFC} / \mathrm{mL}$ & {$[69]$} \\
\hline $\begin{array}{l}\text { Analizador de aliento fluoroétrico } \\
\text { (RBS) }\end{array}$ & Ag85B & 50-75 UFC/mL & {$[68]$} \\
\hline $\begin{array}{l}\text { Electrodo de carbono serigrafiado } \\
\text { ॥ (SPCEII) }\end{array}$ & Ag360 y Ag23I & Ing/mL & {$[7 \mid]$} \\
\hline $\begin{array}{l}\text { Biosensores basados } \\
\text { en la hibridación de ADN }\end{array}$ & $\begin{array}{l}\text { Secuencias específicas de ADN de } \\
\text { Mycobacterium tuberculosis }\end{array}$ & I,25 ng/mL & {$[73]$} \\
\hline \multicolumn{4}{|l|}{ UFC: Unidades Formadoras de Colonias } \\
\hline
\end{tabular}

Finalmente, en la tabla 3 se resumen algunas características de los diversos tipos de pruebas diagnósticas conocidas para la detección de la tuberculosis, presentando las ventajas y desventajas de cada ensayo. 


\begin{tabular}{|c|c|c|c|}
\hline $\begin{array}{l}\text { Método diagnóstico } \\
\text { para tuberculosis }\end{array}$ & $\begin{array}{l}\text { Tiempo de entrega de } \\
\text { resultados }\end{array}$ & Ventajas & Desventajas \\
\hline $\begin{array}{l}\text { Prueba cutánea } \\
\text { con PPD }\end{array}$ & 2 a 3 días & $\begin{array}{l}\text { No requiere preparación de } \\
\text { la muestra ni alta tecnología. } \\
\text { Presenta un bajo costo y es } \\
\text { fácil de aplicar y leer }\end{array}$ & $\begin{array}{l}\text { Alta reactividad cruzada con la } \\
\text { vacuna del } B C G \text {, por micobacterias } \\
\text { no tuberculosas y } \mathrm{VIH}\end{array}$ \\
\hline Baciloscopia & I a 2 días & $\begin{array}{l}\text { Es sencilla y rápida. Detecta la } \\
\text { presencia del bacilo }\end{array}$ & $\begin{array}{l}\text { Muestra difícil de tomar, no es } \\
\text { una prueba específica para Myco- } \\
\text { bacterium tuberculosis, tiene baja } \\
\text { sensibilidad y requiere para la } \\
\text { detección una alta carga bacilar } \\
\text { (5.000- } 10.000 \text { bacilos } / \mathrm{mL})\end{array}$ \\
\hline Cultivo & $\begin{array}{l}\text { Líquido: } 5 \text { a } 10 \text { días } \\
\text { Sólido: } 4 \text { a } 8 \text { semanas }\end{array}$ & Es sencillo y económico & $\begin{array}{l}\text { Es muy demorado para la entrega } \\
\text { de resultados }\end{array}$ \\
\hline Serodiagnóstico & 2 a 3 horas & $\begin{array}{l}\text { Son rápidos y no requieren } \\
\text { un laboratorio muy sofisticado }\end{array}$ & $\begin{array}{l}\text { Necesita pretratamiento de la } \\
\text { muestra, hay dificultades en la } \\
\text { interpretación de resultados por } \\
\text { desconocimiento en la dinámica } \\
\text { de aparición de anticuerpos y su } \\
\text { duración }\end{array}$ \\
\hline $\begin{array}{l}\text { Técnicas } \\
\text { moleculares }\end{array}$ & $\begin{array}{l}\text { Extracción deADN: } 24 \text { a } \\
48 \text { horas } \\
\text { PCR: } 4 \text { horas } \\
\text { Secuenciación automatizada: } \\
4 \text { horas }\end{array}$ & $\begin{array}{l}\text { Son pruebas de alta sensibili- } \\
\text { dad y especificidad }\end{array}$ & $\begin{array}{l}\text { Requiere instrumentación costosa, } \\
\text { tiempo y no se recomienda para } \\
\text { su uso rutinario en países de bajos } \\
\text { recursos }\end{array}$ \\
\hline Biosensores & I a 3 horas & $\begin{array}{l}\text { Son reutilizables y pueden } \\
\text { ofrecer una detección rápida, } \\
\text { sensible y específica }\end{array}$ & $\begin{array}{l}\text { Se deben miniaturizar para ser } \\
\text { portables y bajar costos }\end{array}$ \\
\hline
\end{tabular}

\section{Visión general de los avances en el desarrollo y perspectivas en el diagnóstico de la tuberculosis}

Actualmente, más de 50 empresas se encuentran desarrollando nuevas pruebas de diagnóstico de tuberculosis, empleando diversas tecnologías de punta. Sin embargo, la mayoría de estas nuevas tecnologías requieren laboratorios sofisticados y todavía utilizan las muestras de esputo para la detección. La tabla 4 resume algunas pruebas diagnósticas propuestas y su estado actual de desarrollo.

Teniendo en cuenta este panorama en rápida evolución, la Organización Mundial de la Salud ha establecido un proceso sistemático para la evaluación oportuna de la evidencia y la formulación de políticas para las técnicas de diagnósticos de tuberculosis, las cuales se pueden resumir en cinco fases: a) investigación y desarrollo, b) evaluación y demostración, c) validación, d) fase de captación de evidencia y e) escalado y políticas de perfeccionamiento [74-76].

En la tabla 5 se muestran los métodos y tipos de pruebas de diagnóstico asequibles en el mercado, las cuales se agrupan por estado de validación y aprobación por parte de la Organización Mundial de la Salud. 


\begin{tabular}{|c|c|c|}
\hline Nombre de la prueba & Desarrollador/país & Tipo/muestra \\
\hline \multicolumn{3}{|c|}{ Tecnologías moleculares } \\
\hline Alere Q & $\begin{array}{l}\text { Alere Inc., Estados } \\
\text { Unidos }\end{array}$ & $\begin{array}{l}\text { Plataforma de diagnóstico mole- } \\
\text { cular para escanear Mycobacte- } \\
\text { rium tuberculosis y su resistencia }\end{array}$ \\
\hline B-SMART & $\begin{array}{l}\text { Laboratory Corporation } \\
\text { of America Holdings } \\
\text { (LabCorp), Estados } \\
\text { Unidos }\end{array}$ & $\begin{array}{l}\text { Combina la amplificación de áci- } \\
\text { dos nucleicos y la detección con } \\
\text { fenotipos de pruebas rápidas de } \\
\text { sensibilidad a los medicamentos } \\
\text { para detectar Mycobacterium } \\
\text { tuberculosis y determina la resis- } \\
\text { tencia a drogas anti-tuberculosis, } \\
\text { incluyendo pirazinamida }\end{array}$ \\
\hline $\begin{array}{l}\text { Genedrive MTB/ } \\
\text { RIF ID }\end{array}$ & $\begin{array}{l}\text { Epistem Ltd., Reino } \\
\text { Unido }\end{array}$ & $\begin{array}{l}\text { Reacción en cadena de la polime- } \\
\text { rasa en tiempo real para tuber- } \\
\text { culosis y resistencia a rifampicina }\end{array}$ \\
\hline GeneXpert XDR & $\begin{array}{l}\text { Cepheid Inc., Estados } \\
\text { Unidos }\end{array}$ & $\begin{array}{l}\text { Reacción en cadena de la po- } \\
\text { limerasa en cartuchos para la } \\
\text { detección de tuberculosis extre- } \\
\text { madamente resistente (XDR) en } \\
\text { plataforma GeneXpert }\end{array}$ \\
\hline $\begin{array}{l}\text { Truelab/Truenat } \\
\text { MTB }\end{array}$ & $\begin{array}{l}\text { Molbio/Bigtec Diag- } \\
\text { nostics, India }\end{array}$ & $\begin{array}{l}\text { Chip basado en algoritmo mo- } \\
\text { dificado para la amplificación de } \\
\text { ácidos nucleicos (NAAT) de } \\
\text { Mycobacterium tuberculosis. Fun- } \\
\text { ciona con un dispositivo portátil }\end{array}$ \\
\hline $\begin{array}{l}\text { Estuche de diagnós- } \\
\text { tico NATeasy TB }\end{array}$ & $\begin{array}{l}\text { Ustar Biotechnologies } \\
\text { Ltd., China }\end{array}$ & $\begin{array}{l}\text { Amplificación de ácidos nucleicos } \\
\text { isotérmica y detección en flujo } \\
\text { lateral }\end{array}$ \\
\hline $\begin{array}{l}\text { LATE-PCR con } \\
\text { sondas Lights-On/ } \\
\text { Lights-Off y tecnología } \\
\text { PrimeSafe }\end{array}$ & $\begin{array}{l}\text { Stellenbosch University, } \\
\text { Sudáfrica } \\
\text { Desarrollado por Bran- } \\
\text { deis University, Estados } \\
\text { Unidos }\end{array}$ & $\begin{array}{l}\text { Reacción en la cadena de la polime- } \\
\text { rasa para la detección simultánea } \\
\text { de Mycobacterium tuberculosis y } \\
\text { resistencia a inhibidores, rifampicina, } \\
\text { etambutol e inyectables }\end{array}$ \\
\hline
\end{tabular}

\section{Tecnologías no moleculares}

$\begin{array}{ll}\text { Alere } & \text { Alere Inc., Estados } \\ & \text { Unidos }\end{array}$

$\begin{array}{ll}\text { TB Rapid Screen } & \text { Global BioDiagnostics } \\ & \text { Corp., Estados Unidos, } \\ & \text { con soporte de Founda- } \\ & \text { tion for Innovative New } \\ & \text { Diagnostics (FIND), Suiza } \\ \text { TBDx } & \text { Signature Mapping } \\ & \text { Medical Sciences Inc., } \\ & \text { Estados Unidos }\end{array}$

Prueba de orina de flujo lateral que detecta la proteína LAM en adultos con $\mathrm{VIH}$

Indicadores enzimáticos de referencia para la detección de $\beta$-lactamasa producida por las bacterias vivas en muestras de esputo

Sistema de carga automatizada para lectura de la baciloscopia

En desarrollo, estudios de campo en curso

Disponible en el mercado, con estudios de campo en curso

En desarrollo. Se espera que utilice un lector de fluorescencia simple, de bajo costo

Epistem fue galardonado con acreditación CE/IVD (acreditación de la Unión Europea para productos sanitarios)

Licenciado

Disponible en el mercado de India

completos

Disponible en el mercado

No aprobada por la OMS Solicitud de registro en curso en China

En desarrollo. Se probará con muestras clínicas en África

\section{Tecnologías basadas en cultivos}

$\begin{array}{lll}\text { BNP Middlebrook } & \text { Nano Logix Inc., } & \text { Cultivo } \\ & \text { Estados Unidos } & \\ \text { MDR-XDR TB } & \text { Foundation for Innova- } & \text { Prueba colorimétrica rápida para } \\ \text { Color Test } & \text { tive New Diagnostics } & \text { la susceptibilidad a fármacos } \\ & \text { (FIND), Suiza } & \\ & \text { Imperial College } & \\ & \text { London, Reino Unido }\end{array}$

En desarrollo

En desarrollo, con estudio de viabilidad para comenzar 


$\begin{array}{lll}\text { TREK Sensititre } & \text { Trek Diagnostic } & \text { Usa una placa de microdilución } \\ \text { MYCOTB MIC plate } & \text { Systems Inc., Estados } & \text { en seco que contiene antibióticos } \\ & \text { Unidos } & \text { liofilizados para la determinación } \\ & \text { Thermo Fisher } & \text { de las concentraciones inhibitorias } \\ & \text { Scientific Inc., Estados } & \text { mínimas para medicamentos anti- } \\ & \text { Unidos } & \text { tuberculosis }\end{array}$

Componentes orgánicos volátiles

BreathLink Menssana Research Inc., Estados Unidos

Prototype breathalyzer device

Next Dimensions Technology Inc., Estados Unidos
Componentes orgánicos volátiles

Para determinar la tuberculosis activa y la tuberculosis resistente a medicamentos
En desarrollo, con estudios de campo en análisis

En desarrollo, con estudios de factibilidad, pero ha recibido registro de conformidad Europea (del inglés, European Conformity), mandatorio para los productos que van a ser vendidos en la Unión Europea

En desarrollo

Continúa la financiación por la Fundación Bill \& Melinda Gates (BMGF) para el mejoramiento

Tabla 5. Recomendaciones de la Organización Mundial de la Salud para nuevos métodos de diagnósticos de tuberculosis

Métodos evaluados por la Organización Mundial de la Salud pendientes de aprobación por falta de evidencia

Tecnologías moleculares

- TB LAMP. Eiken Chemical Co.,Ltd., Japón

- Genotype MTBDRsl. Hain Lifescience GmbH, Alemania

Métodos que se encuentran en el mercado que no han sido evaluados por la Organización Mundial de la Salud

Tecnologías moleculares

- iCubate System. iCubate Inc., Estados Unidos

- TB drug resistance array. Capital Bio Corp., China

- EasyNAT TB. Ustar Biotechnologies Ltd., China

- Truelab/Truenat MTB. Molbio/Bigtec Diagnostics, India

Tecnologías no moleculares

- $\quad$ Alere Determine TB-LAM. Alere Inc., Estados Unidos

Técnicas evaluadas por la por la Organización Mundial de la Salud, no recomendadas

- Serodiagnósticos comerciales

- Ensayos de liberación de interferón-gamma para la detección de tuberculosis activa

Tecnologías avaladas y recomendadas por la Organización Mundial de la Salud

Tecnologías moleculares

- Xpert MTB/RIF ${ }^{\circledR}$. Cepheid Inc., Estados Unidos

- INNO-LiPA ${ }^{\circledR}$. Innogenetics N.V., Bélgica

Microscopía

- Ziehl-Neelsen y métodos de microscopía fluorescente

Tecnología basadas en cultivos

- Sistemas comerciales de cultivos líquidos

- Métodos de ensayo de cultivo no comerciales y pruebas de susceptibilidad a fármacos

\section{Financiamiento en la investigación de nuevos métodos de diagnóstico para la tuberculosis}

La Organización Mundial de la Salud, en su último informe sobre las tendencias de financiación de la investigación en tuberculosis (2005-20।4), indicó que la financiación para el diag- 
nóstico de la tuberculosis en 2014 fue de US\$ 65.37I.547 [77]. Sin embargo, el Plan Mundial para Detener la Tuberculosis (The Global Plan to Stop TB), 20II-20I5, estimó un valor de presupuesto requerido para este tipo de investigaciones de US $\$ 3.700 .000 .000 .000$ anuales [78], estableciendo una brecha económica que se refleja en la frecuencia e impacto de los desarrollos en esta área. Actualmente, las entidades que financian la mayoría de las investigaciones en el diagnóstico de la tuberculosis son los Institutos Nacionales de la Salud (NIH) de los Estados Unidos/Instituto Nacional de Alergia y Enfermedades Infecciosas (NIAID), la Fundación Bill \& Melinda Gates (BMGF), la empresa privada Otsuka Pharmaceutical y la Comisión Europea [77].

\section{Conclusiones}

La identificación de los casos activos de tuberculosis es la clave para resolver el problema de salud pública que representa hoy en día esta enfermedad. Las técnicas tradicionales que se han usado por décadas para la detección de la tuberculosis requieren ser actualizadas y mejoradas, de manera que beneficien principalmente a la población de regiones endémicas vulnerables. Una de las principales dificultades para el control de la tuberculosis es la falta de un diagnóstico rápido, que se refleja con los altos índices de mortalidad ocasionados por esta enfermedad aún con la existencia de tratamientos efectivos antituberculosos.

Un aporte importante a esta problemática proviene del desarrollo y aplicación de la tecnología de los biosensores, la cual viene tomando fuerza en los últimos años, convirtiéndose en una de las áreas de investigación emergentes más prometedoras para la detección rápida de Mycobacterium tuberculosis. No obstante, esta tecnología, como muchas otras mencionadas, debe enfrentar numerosos desafíos antes de ser constituida como un nuevo método de diagnóstico validado y recomendado por la Organización Mundial de la Salud tales como la miniaturización, la portabilidad y la disminución de costos de los dispositivos, el aumento de la capacidad de adaptación y la flexibilidad para la detección multianalito (caso de la coinfección con el VIH), el aumento de la sensibilidad y la especificidad, y la reducción de reacciones cruzadas con matrices biológicas, entre otros.

La obtención de estas características podría aumentar el rendimiento de estos biosensores con la disminución de costos en su desarrollo, lo que favorecería su implementación en regiones endémicas vulnerables. En este sentido, es necesario el avance continuo de las áreas del conocimiento que envuelven el desarrollo de estos dispositivos para logar el diseño y validación de las pruebas, que marquen la diferencia definitiva en el diagnóstico de la tuberculosis. Además, se deben consolidar esfuerzos entre las entidades privadas y gubernamentales para financiar la investigación de centros y universidades con potencial de desarrollo de nuevos métodos de diagnóstico clínico de la tuberculosis.

\section{Bibliografía}

I. World Health Organization. Global tuberculosis report 2015 (ed 20a). Francia: World Health Organization; 2015.

2. Wu CY, Hu HY, Pu CY, Huang N, Shen HC, Li
$\mathrm{CP}$, et al. Pulmonary tuberculosis increases the risk of lung cancer: a population-based cohort study. Cancer 2011; 117: 618-624.

3. Stewart BW, Wild CP. World Cancer Report 
2014. Francia: International Agency for Research on Cancer; 2014.

4. Lönnroth K, Raviglione M. Global epidemiology of tuberculosis: prospects for control. Semin Respir Crit Care Med 2008; 29: 48I-49I.

5. Stop TB Partnership, World Health Organization. The Stop TB strategy : building on and enhancing DOTS to meet the TB-related Millennium Development Goals. Ginebra, Suiza: World Health Organization; 2006.

6. Lönnroth K, Jaramillo E, Williams BG, Dye C, Raviglione M. Drivers of tuberculosis epidemics: the role of risk factors and social determinants. Soc Sci Med 2009; 68: 2240-2246.

7. World Health Organization. Gear up to End TB: Introducing the WHO End TB Strategy. 20I5. Disponible: http://www.who.int/tb/End_TB_brochure.pdf. Consultado: agosto 2014.

8. World Health Organization. Xpert MTB/RIF implementation manual. Technical and operational 'how-to': practical considerations. Ginebra, Suiza: WHO Press; 2014.

9. Lawn SD, Mwaba P, Bates M, Piatek A, Alexan$\operatorname{der} \mathrm{H}$, Marais $\mathrm{BJ}$, et al. Advances in tuberculosis diagnostics: the Xpert MTB/RIF assay and future prospects for a point-of-care test. Lancet Infect Dis 2013; 13: 349-36।.

10. Zhou L, He X, He D, Wang K, Qin D. Biosensing technologies for Mycobacterium tuberculosis detection: status and new developments. Clin Dev Immunol 20 I I; 20 I I: 193963.

II. Pfyffer GE. Mycobacterium: General Characteristics, Laboratory Detection, and Staining. En: Jorgensen JH, Pfaller MA, Carroll KC, Funke G, Landry ML, Richter SS, et al., eds. Manual of Clinical Microbiology. Vol. I (ed I la). Washington D.C., Estados Unidos: ASM Press; 2015: 536569.

12. Glickman MS, Jacobs WR, Jr. Microbial pathogenesis of Mycobacterium tuberculosis: dawn of a discipline. Cell 200I; 104: 477-485.

13. Torrelles JB, Schlesinger LS. Diversity in Mycobacterium tuberculosis mannosylated cell wall determinants impacts adaptation to the host. Tuberculosis (Edinb) 2010; 90: 84-93.

14. Schwartzman K. Latent tuberculosis infection: old problem, new priorities. CMAJ 2002; I66: 759-761.

15. Grzybowski S, Barnett GD, Styblo K. Contacts of cases of active pulmonary tuberculosis. Bull Int Union Tuberc 1975; 50: 90-106.

16. Sayarlioglu M, Inanc M, Kamali S, Cefle A, Karaman O, Gul A, et al. Tuberculosis in Turkish patients with systemic lupus erythematosus: increased frequency of extrapulmonary localization. Lupus 2004; I 3: 274-278.

17. Kipp AM, Stout JE, Hamilton CD, Van Rie A.
Extrapulmonary tuberculosis, human immunodeficiency virus, and foreign birth in North Carolina, 1993 - 2006. BMC Public Health 2008; 8: 107.

18. Pethe K, Alonso S, Biet F, Delogu G, Brennan MJ, Locht $C$, et al. The heparin-binding haemagglutinin of $M$. tuberculosis is required for extrapulmonary dissemination. Nature 2001; 4I2: 190-194.

19. Kong Y, Cave MD, Zhang L, Foxman B, Marrs $\mathrm{CF}$, Bates $\mathrm{JH}$, et al. Association between Mycobacterium tuberculosis Beijing/W lineage strain infection and extrathoracic tuberculosis: Insights from epidemiologic and clinical characterization of the three principal genetic groups of M. tuberculosis clinical isolates. J Clin Microbiol 2007; 45: 409-4I4.

20. Webster AS, Shandera WX. The extrapulmonary dissemination of tuberculosis: A meta-analysis. Int J Mycobacteriol 20|4; 3: 9-16.

21. Antony SJ, Harrell V, Christie JD, Adams HG, Rumley RL. Clinical differences between pulmonary and extrapulmonary tuberculosis: a 5-year retrospective study. J Natl Med Assoc 1995; 87: 187-192.

22. World Health Organization. Global tuberculosis report 2014. Francia: World Health Organization; 2014

23. Winn WC, Allen SD, Janda WM, Koneman EW, Procop GW, Schrenckenberger PC, et al. Bacilos grampositivos aerobios y facultativos. En: Koneman Diagnóstico microbiológico (ed 6a). Buenos Aires, Argentina: Editorial Médica Panamericana; 2008: 728-730.

24. Thanyani ST, Roberts V, Siko DG, Vrey P, Verschoor JA. A novel application of affinity biosensor technology to detect antibodies to mycolic acid in tuberculosis patients. J Immunol Methods 2008; 332: 61-72.

25. Kunst $\mathbf{H}$. Diagnosis of latent tuberculosis infection: the potential role of new technologies. Respir Med 2006; 100: 2098-2106.

26. Araujo Z, Acosta M, Escobar $\mathrm{H}$, Baños R, Fernández de Larrea $C$, Rivas-Santiago B. Respuesta inmunitaria en tuberculosis y el papel de los antígenos de secreción de Mycobacterium tuberculosis en la protección, patología y diagnóstico: Revisión. Invest Clín 2008; 49: 4II-441.

27. Al Zahrani K, Al Jahdali H, Menzies D. Does size matter? Utility of size of tuberculin reactions for the diagnosis of mycobacterial disease. Am J Respir Crit Care Med 2000; 162: |419-1422.

28. Caminero Luna JA, Casal Román M, Ausina Ruiz V, Pina Gutiérrez JM, Sauret Valet J. Diagnóstico de la tuberculosis. Arch Bronconeumol 1996; 32: 85-99.

29. Organización Panamericana de la Salud. Manual para el diagnóstico bacteriológico de la tuberculosis. Parte I. Baciloscopia; 2008. 
30. Frieden TR. Tuberculosis: Detección de casos, tratamiento y vigilancia. Preguntas y respuestas: Kurt Toman (ed 2a). Washington D.C., Estados Unidos: Organización Panamericana de la Salud; 2006.

31. American Thoracic Society, Centers for Disease Control and Prevention. Diagnostic Standards and Classification of Tuberculosis in Adults and Children. This official statement of the American Thoracic Society and the Centers for Disease Control and Prevention was adopted by the ATS Board of Directors, July 1999 This statement was endorsed by the Council of the Infectious Disease Society of America, September 1999. Am J Respir Crit Care Med 2000; 161: 1376-1395

32. Chan ED, Heifets L, Iseman MD. Immunologic diagnosis of tuberculosis: a review. Tuber Lung Dis 2000; 80: | $31-\mid 40$.

33. Perkins MD, Roscigno G, Zumla A. Progress towards improved tuberculosis diagnostics for developing countries. Lancet 2006; 367: 942-943.

34. Organización Panamericana de la Salud. Manual para el diagnóstico bacteriológico de la tuberculosis. Parte 2. Cultivo; 2008.

35. Frieden TR, Sterling TR, Munsiff SS, Watt CJ, Dye C. Tuberculosis. Lancet 2003; 362: 887899.

36. Cascante JA, Pascal I, Eguía VM, Hueto J. Diagnóstico de la infección tuberculosa. An Sist Sanit Navar 2007; 30: 49-65.

37. Hepple P, Ford N, McNerney R. Microscopy compared to culture for the diagnosis of tuberculosis in induced sputum samples: a systematic review. Int J Tuberc Lung Dis 2012; 16: 579-588.

38. Heifetes LB, Good RC. Current Laboratory methods for the diagnosis of tuberculosis. En: Bloom BM, ed. Tuberculosis: Pathogenesis, protection and control. Washington D.C., Estados Unidos: ASM Press; 1994: 85-I 10.

39. Solórzano RF, Varela-Martínez C. Métodos Diagnósticos en Tuberculosis: lo convencional y lo nuevo. Rev Med Hondur 2006; 74: 93- I0I.

40. Reino Unido de Gran Bretaña, Department of Health, Public Health England. Molecular diagnosis of tuberculosis: Information for healthcare professionals. Londres, Reino Unido. 2015. Disponible: https://www.gov.uk/government/uploads/system/uploads/attachment_data/ file/489198/Molecular_diagnosis_of_tuberculosis_for_healthcare_professionals.pdf. Consultado: agosto 2015.

41. Bekmurzayeva A, Sypabekova M, Kanayeva D. Tuberculosis diagnosis using immunodominant, secreted antigens of Mycobacterium tuberculosis. Tuberculosis (Edinb) 2013; 93: 381-388.

42. da Silva CF, Ueki SY, Geiger Dde C, Leao SC. hsp65 PCR-restriction enzyme analysis (PRA) for identification of mycobacteria in the clinical laboratory. Rev Inst Med Trop Sao Paulo 200 I; 43: 25-28.

43. Katoch V. Advances in Molecular Diagnosis of Tuberculosis. MJAFI 2003; 59.

44. Mallard K, McNerney R, Crampin AC, Houben $\mathrm{R}$, Ndlovu R, Munthali L, et al. Molecular detection of mixed infections of Mycobacterium tuberculosis strains in sputum samples from patients in Karonga District, Malawi. J Clin Microbiol 2010; 48: 4512-45।8.

45. Puerto G, Castro CM, Ribón W. Reacción en cadena de la polimerasa: una contribución para el diagnóstico de la tuberculosis extrapulmonar y de las micobacteriosis. Infectio 2007; I I: 97- 100.

46. Tiwari RP, Hattikudur NS, Bharmal RN, Kartikeyan S, Deshmukh NM, Bisen PS. Modern approaches to a rapid diagnosis of tuberculosis: promises and challenges ahead. Tuberculosis (Edinb) 2007; 87: 193-201.

47. Pai M, Kalantri S, Dheda K. New tools and emerging technologies for the diagnosis of tuberculosis: part II. Active tuberculosis and drug resistance. Expert Rev Mol Diagn 2006; 6: 423432.

48. World Health Organization, United Nations Children's Fund, Joint United Nations Programme on HIVIAIDS (UNAIDS), Médecins Sans Frontières. Sources and prices of selected medicines and diagnostics for people living with HIV/AIDS (ed 6a). Francia; 2005.

49. Clayden P, Collins S, Daniels C, Frick M, Harrington $M$, Horn T, et al. 2013 Pipeline report: HIV, hepatitis $C$ virus (HCV), and tuberculosis (TB) drugs, diagnostics, vaccines, preventive technologies, research toward a cure, and immune-based and gene therapies in development: HIV i-Base/Treatment Action Group; 2013.

50. Steingart KR, Sohn H, Schiller I, Kloda LA, Boehme CC, Pai M, et al. Xpert(R) MTB/RIF assay for pulmonary tuberculosis and rifampicin resistance in adults. Cochrane Database Syst Rev 2013; 1: |-|3|.

5I. Simonney N, Labrousse H, Ternynck T, Lagrange $\mathrm{PH}$. Recycling of ELISA plates for the serological diagnosis of tuberculosis using a Mycobacterium tuberculosis-specific glycolipid antigen. J Immunol Methods 1996; 199: 101-105.

52. Moran AJ, Treit JD, Whitney JL, Abomoelak B, Houghton R, Skeiky YA, et al. Assessment of the serodiagnostic potential of nine novel proteins from Mycobacterium tuberculosis. FEMS Microbiol Lett 2001; 198: 31-36.

53. Abebe F, Holm-Hansen C, Wiker HG, Bjune G. Progress in serodiagnosis of Mycobacterium tuberculosis infection. Scand J Immunol 2007; 66: |76-19|.

54. Laal S, Skeiky YAW. Immune-Based Methods. 
En: Cole ST, Davis Eisenach K, McMurray DN, Jacobs WR, Jr., eds. Tuberculosis and the tubercle bacillus. Washington D.C., Estados Unidos: ASM Press; 2005: 7I-84.

55. Wallis RS, Doherty TM, Onyebujoh P, Vahedi M, Laang $\mathrm{H}$, Olesen $\mathrm{O}$, et al. Biomarkers for tuberculosis disease activity, cure, and relapse. Lancet Infect Dis 2009; 9: 162-172.

56. Parida SK, Kaufmann SH. The quest for biomarkers in tuberculosis. Drug Discov Today 2010; 15: 148-157.

57. Wallis RS, Pai M, Menzies D, Doherty TM, Walzl G, Perkins MD, et al. Biomarkers and diagnostics for tuberculosis: progress, needs, and translation into practice. Lancet 20 I0; 375: 1920 1937.

58. Wallis RS, Kim P, Cole S, Hanna D, Andrade $\mathrm{BB}$, Maeurer $\mathrm{M}$, et al. Tuberculosis biomarkers discovery: developments, needs, and challenges. Lancet Infect Dis 2013; 13: 362-372.

59. Bill \& Melinda Gates Foundation. Gates Foundation Invests in Cutting-Edge Research to Diagnose Tuberculosis in Developing Countries. 2012. Disponible: http://www.gatesfoundation. org/Media-Center/Press-Releases/2012/02/ Gates-Foundation-Invests-in-CuttingEdge-Research-to-Diagnose-Tuberculosis-in-Developing-Countries. Consultado: agosto 2015.

60. Tynan K, Blasband A, Neuwald P, Penny L, Urdea M. Biomarkers for Infectious Disease Diagnostics in the Developing World: Diagnosis of Tuberculosis in HIV Positive and HIV Negative Individuals. California, Estados Unidos: Halteres Associates, LCC; 2009.

6I. Nagel B, Dellweg H, Gierasch LM. Glossary for chemists of terms used in biotechnology (IUPAC Recommendations 1992). Pure Appl Chem 1992; 64: 143-168.

62. Guilbault GG, Pravda M, Kreuzer M, O’Sullivan CK. Biosensors - 42 Years and Counting. Anal Lett 2004; 37: |48|-| 496.

63. Montoya A, Ocampo A, March C. Fundamentals of Piezoelectric Immunosensors. En: Arnau Vives A, ed. Piezoelectric Transducers and Applications (ed 2a). Berlín, Alemania: Springer-Verlag Berlin Heidelberg; 2008: 289-306.

64. Anjum V, Pundir C. Biosensors: Future Analytical Tools. Sensors Transd J 2007; 76: 937-944.

65. He F, Zhang L. Rapid diagnosis of M. tuberculosis using a piezoelectric immunosensor. Anal Sci 2002; 18: 397-40 I.

66. Hiatt LA, Cliffel DE. Real-time Recognition of
Mycobacterium tuberculosis and Lipoarabinomannan using the Quartz Crystal Microbalance. Sens Actuators B Chem 2012; 174: 245-252.

67. Ren J, He F, Yi S, Cui X. A new MSPQC for rapid growth and detection of Mycobacterium tuberculosis. Biosens Bioelectron 2008; 24: $403-$ 409.

68. McNerney R, Wondafrash BA, Amena K, Tesfaye A, McCash EM, Murray NJ. Field test of a novel detection device for Mycobacterium tuberculosis antigen in cough. BMC Infect Dis 2010; 10: 161.

69. Chun AL. Nanoparticles offer hope for TB detection. Nat Nanotechnol 2009; 4: 698-699.

70. Lee H, Sun E, Ham D, Weissleder R. Chip-NMR biosensor for detection and molecular analysis of cells. Nat Med 2008; 14: 869-874.

7I. Diaz-Gonzalez M, Gonzalez-Garcia MB, CostaGarcia A. Immunosensor for Mycobacterium tuberculosis on screen-printed carbon electrodes. Biosens Bioelectron 2005; 20: 2035-2043.

72. Wang S, Inci F, De Libero G, Singhal A, Demirci $U$. Point-of-care assays for tuberculosis: role of nanotechnology/microfluidics. Biotechnol Adv 2013; 31: 438-449

73. Thiruppathiraja C, Kamatchiammal S, AdaikkaPpan P, Santhosh DJ, Alagar M. Specific detection of Mycobacterium sp. genomic DNA using dual labeled gold nanoparticle based electrochemical biosensor. Anal Biochem 2011; 417 73-79.

74. Costa P, Amaro A, Botelho A, Inacio J, Baptista PV. Gold nanoprobe assay for the identification of mycobacteria of the Mycobacterium tuberculosis complex. Clin Microbiol Infect 2010; 16: | 464- | 469.

75. World Health Organization. Global tuberculosis report 2013. Francia: World Health Organization; 2013.

76. UNITAID. Tuberculosis: Diagnostics Technology and Market Landscape (ed 2a). Suiza: World Health Organization; 2013.

77. Treatment Action Group. 2015 Report on Tuberculosis. Research Funding Trends, 20052014: A Decade of Data. Nueva York, Estados Unidos: Stop TB Partnership; 2015.

78. World Health Organization, Stop TB Partnership. The global plan to stop TB 20II-20I5. Ginebra, Suiza: WHO Press. 2010. Disponible: http://www.stoptb.org/assets/documents/global/ plan/tb_globalplantostoptb20 I I-20I5.pdf. Consultado: agosto 2015 